\title{
PRINSIP MAKSIM KEDERMAWANAN DALAM NOVEL HATI SUHITA KARYA KHILMA ANIS
}

\author{
Asfa A'idina ${ }^{1}$ \\ Pendidikan Bahasa dan Sastra Indonesia, Fakultas Ilmu Pendidikan, Universitas Hasyim Asy'ari \\ aidinaasfa@gmail.com \\ Rusli Ilham Fadli ${ }^{2}$ \\ Pendidikan Bahasa dan Sastra Indonesia, Fakultas Ilmu Pendidikan, Universitas Hasyim Asy'ari \\ rusliilhamfadli@gmail.com \\ Yulianah Prihatin ${ }^{3}$ \\ Pendidikan Bahasa dan Sastra Indonesia, Fakultas Ilmu Pendidikan, Universitas Hasyim Asy'ari \\ yuliaana553@gmail.com
}

\begin{abstract}
Abstrak
Penelitian ini bertujuan untuk mengetahui dan mendeskripsikan maksim kedermawanan dalam novel Hati Suhita karya Khilma Anis. Maksim kedermawanan termasuk dalam enam maksim kesantunan berahasa yang didiutarakan oleh Leech yaitu maksim maksim kebijaksanaan, kedermawanan, pujian, kesederhanaan, pemufakatan dan kesimpatisan. Pendeskripsian maksim kedermawanan diperoleh melalui dialog antartokoh dalam novel Hati Suhita. Penelitian in menggunakan metode kualitatif, jadi data yang sudah didapatkan dideskripsikan. Teknik pengumpulan data yang dipakai dalam penelitian ini adalah teknik studi pustaka, teknik baca, dan teknik catat. Sedangkan teknik analisis data yang dipakai pada penelitian ini adalah teknik kajian isi. Berdasarkan hasil penelitian didapatkan bahwa terdapat 24 tuturan yang termasuk dalam maksim kedermawanan.
\end{abstract}

Kata Kunci: maksim kedermawanan, novel

\begin{abstract}
This study aims to determine and describe the generosity of maxims in the novel Hati Suhita by Khilma Anis. The maxim of generosity is included in the six maxims of language politeness expressed by Leech, namely the maxim of wisdom, generosity, praise, simplicity, consensus and sympathy. Describing the maxim of generosity is obtained through dialogue between figures in the novel Hati Suhita. This research uses qualitative methods, so the data that has been obtained is described. Data collection techniques used in this study are literature study techniques, reading techniques, and note taking techniques. While the data analysis technique used in this study is the content study technique. Based on the results of the study found that there are 24 utterances included in the maxim of generosity.
\end{abstract}

Keywords: generosity maxim, novel

\section{PENDAHULUAN}

Kesantunan berbahasa merupakan sebuah etika dalam berkomunikasi di lingkungan masyarakat sosial dengan menggunakan pilihan kata yang baik dan tepat, serta melihat kondisi lawan bicara, situasi, tempat, waktu, dan tujuan dari sebuah komunikasi. Hal tersebut sesuai dengan budaya dalam masyarakat bahwa berkomunikasi dengan menggunakan bahasa yang baik dan santun akan menunjukkan sebuah pribadi yang santun, berbudaya, dan berpendidikan. Di era modern ini karya sastra berkembang dengan pesat, selain karya sastra umum juga terdapat karya sastra yang berlatar belakang agama.Di Indonesia novel-novel yang berlatar belakang agama sudah sangat banyak ditemui. Hal tersebut tidak lepas dari sosiologi dan latar belakang pengarangnya. Banyak penulispenulis yang berasal dari kalangan pesantren memberikan pengaruh besar bagi karyakarya yang ditulis, seperti Habiburrahman El-Shirazy, Ma'mun Affany, Asma Nadia, Tony Rosyid, Khilma Anis dan masih 
banyak lainnya. Mereka merupakan penulis yang berlatar belakang pesantren sehingga mereka menjadikan pesantren sebagai setting dalam karya-karya yang diciptakan. Hal-hal yang dituangkan dalam karyanya sesuai dengan apa yang pernah mereka alami di lingkungan pesantren. Tradisi pesantren melekat pada karya mereka, dari segi kegiatan yang biasa dilakukan di pesantren, adab atau sopan santun yang dijunjung tinggi dalam adat pesantern, dan segala hal yang berhubungan dengan dunia kepesantrenan.

Penelitian ini menggunakan novel Hati Suhita karya Khilma Anis sebagai objek penelitian yang dilatarbelakangi oleh fakta bahwa prinsip kesantunan berbahasa itu penting baik secara lisan maupun dalam bentuk tulisan. Novel sebagai karya tulis juga harus menggunakan tataran dan percakapan yang mencakup prinsip kesantunan berbahasa. Beberapa hal yang mendasari yaitu Pertama, latar budaya dari kehidupan pengarang menjadi pertimbangan dalam pemilihan objek penelitian.Penulis beranggapan bahwa pengarang yang lahir dan hidup dalam kebudayaan Jawa masih memegang erat nilai kesopansantunan, misalnya santun dalam berbahasa. Khilma Anis seorang perempuan Jawa yang sangat cinta pada dunia wayang, keris, serat, babad, dan cerita kolosal yang Ia dapatkan sejak kecil dari kakeknya membuat tulisannya khas berisi dunia batin perempuan Jawa dengan sikap santun, lembut, mikul duwur mendem jero, dan wani-tapa (berani bertapa).

Selain itu, pengarang juga hidup di lingkungan pesantren yang sangat mengedepankan sopan santun baik dalam perbuatan maupun dalam pemilihan kata yang digunakan ketika berbicara/ berkomunikasi dalam kehidupan seharihari. Khilma Anis adalah seorang penulis yang hidup di lingkungan pesantren.la lahir dan tumbuh dalam lingkup dunia pesantren. Hingga saat ini Ia menjadi pengelola pondok pesantren di Jember, oleh karena itu karya-karyanya lekat dengan kehidupan di lingkungan pesantren.

Kedua, pengarang menyuguhkan tokoh utama dengan peran perempuan Jawa yang berkarakter santun, sabar, disiplin, pantang menyerah dan memiliki semangat yang sangat tinggi. Hal tersebut dapat dijadikan sebagai tauladan bagi para perempuan baik dari keturunan Jawa maupun lainnya agar menjadi perempuan hebat yang tetap santun dalam sikap maupun ucapan.

Percakapan di novel ini merupakan sebuah cerminan yang terjadi di dunia nyata sehingga percakapan tersebut dapat dianalisis dengan menggunakan konsep-konsep pragmatik. Kesantunan berbahasa yang terdapat dalam novel tersebut dapat direalisasikan melalui strategi- strategi yang diwujudkan dalam setiap percakapan. Prinsip kesantunan yang digunakan dalam penelitian ini yaotu maksim kedermawanan.

Prinsip kesantunan berbahasa menurut Leech berhubungan dengan dua pihak, yaitu pihak diri dan pihak lain. Pihak diri merupakan penutur, dan pihak lain merupakan pendengar. Pihak lain juga dapat ditujukan kepada pihak ketiga, baik yang ada maupun yang tidak ada pada saat tuturan berlangsung. Leech merumuskan prinsip kesantunannya dalam enam maksim. Maksim adalah kaidah kebahasaan dalam interaksi lingual, maksim juga merupakan bentuk dari pragmatik berdasarkan prinsip kesantunan.

Maksim merupakan acuan dalam mengungkapkan tuturan dengan baik dan sopan, serta menghindari tuturan-turan yang tidak baik dan tidak sopan. Dalam berkomunikasi terdapat beberapa hal yang perlu diperhatikan, salah satunya adalah etika dalam menyampaikan tuturan yaitu kesantunan berbahasa. Bagaimana tuturan dapat diterima oleh penutur di bawah ini adalah prinsip kesantunan berbahasa menurut Leech.

1. Prinsip maksim kebijaksanaan

Prinsip maksim kebijaksanaan adalah prinsip dimana penutur mengurangi keuntungan dalam berkomunikasi dengan lawan tuturnya.Dengan demikian lawan tutur dapat menilai 
bahwa penutur adalah seseorang yang santun.

2. Prinsip maksim kedermawanan

Prinsip maksim kedermawanan adalah prinsip dimana penutur dapat bersikap murah hati dengan mengurangi keuntungan pada dirinya dalam berkomunikasi dan lebih melihat bagaimana cara agar lawan tuturnya dapat mendapatkan keuntungan dalam kegiatan berkomunikasi.

3. Prinsip maksim pujian

Prinsip maksim pujian adalah prinsip maksim yang dimana penutur dapat dianggap seseorang yang santun apabila dalam bertutur memberikan penghargaan pada lawan tuturnya sehinga menghindari terjadinya sesuatu tuturan yang tidak baik, misalnya sebuah cacian, makian, yang membuat lawan tutur tidak nyaman.

4. Prinsip maksim kesederhanaan

Prinsip maksim kesederhanaan adalah suatu prinsip dimana penutur dapat berkomunikasi dengan baik.Diantaranya dengan mengurangi pujian pada dirinya, sehingga lawan tutur dapat menilai penutur sebagai seseorang yang rendah hati dan berprilaku santun.

5. Prinsip maksim pemufakatan

Prinsip maksim pemufakatan adalah suatu prinsip dimana penutur dan lawan tutur sepakat dalam menekankan suatu persetujuan, diharapkan pada maksim ini penutur dan lawan tutur dapat saling menghargai dalam setiap tuturan yang dituturkan.

6. Prinsip maksim kesimpatian

Prinsip maksim kesimpatian adalah suatu maksim imana penutur dapat memberikan rasa simpati kepada lawan tutur dalam kegiatan yang mereka lakukan.

\section{METODE PENELITIAN}

Penelitian ini termasuk jenis penelitian kualitatif. Menurut Moleong (Solihin, Asep. dkk, 2019: 342) metodologi kualitatif adalah suatu prosedur dalam penelitian yang akan mengahasilkan data deskriptif baik berupa kata lisan dan tulisan dari suatu objek yang diamati. Objek pada penelitian ini berupa dialog antar tokoh dalam novel Hati Suhita. Hati Suhita adalah sebuah novel karya Khilma Anis, dengan tebal $405(\mathrm{x}+405)$ halaman, satu jilid, berukuran $14 \times 20,5 \mathrm{~cm}$, cetakan I pada Maret 2019. Novel ini diterbitkan oleh penerbit Telaga Aksara dan bekerjasama dengan Mazaya Media.

Adapun subjek penelitiannya yaitu maksim kedermawanan yang berdasarkan pendapatnya Leech mengenai prinsip kesantunan berbahasa.

Teknik pengumpulan data yang dipakai dalam penelitian ini adalah teknik studi pustaka, teknik baca, dan teknik catat.

Adapun langkah-langkah pengumpulan datanya sebagai berikut:

1. membaca dengan cermat novel Hati Suhita;

2. mengidentifikasi maksim kedermawanan yang digunakan pada novel Hati Suhita;

3. membaca berulang-ulang dialog antartokoh pada novel Hati Suhita untuk memastikan data;

4. mencatat data ke tabel data;

5. mengklasifikasikan data.

Sedangkan teknik analisis data nalisis data penelitian ini akan dilakukan berdasarkan

langkah-langkah berikut:

1. mereduksi data yang terdapat pada novel Hati Suhita;

2. mengenali penanda kesantunan berbahasa maksim kedermawanan pada novel Hati Suhita;

3. menganalisis data sesuai dengan teori kesantunan berbahasa yang dikemukakan Leech;

4. menyimpulkan hasil analisis kesantunan berbahasa yang digunakan pada novel Hati Suhita.

\section{PEMBAHASAN}

Berdasarkan hasil penelitian yang peneliti lakukan, terdapat 24 tuturan dalam dialog 
antartokoh novel Hati Suhita karya Khilma Anis yang mengandung prinsip maksim kedermawanan (MDM). Untuk lebih jelasnya dapat dilihat pada tabel berikut.

\begin{tabular}{|c|c|}
\hline No & Data \\
\hline 1 & $\begin{array}{l}\text { "Ini nomorku, hubungi aku kalau ada } \\
\text { apa-apa dengan anak-anak. Kamu juga } \\
\text { boleh bercerita kapan saja kamu mau." } \\
\text { (MDM: } 20-2 \text { ) }\end{array}$ \\
\hline 2 & $\begin{array}{l}\text { "Ta'pamitke Bu Nyai, ya? ta'ajak ke salon } \\
\text { kamu." } \\
\text { (MDM: 22-4) }\end{array}$ \\
\hline 3 & $\begin{array}{l}\text { "Makanya kamu kuajak kesalon, biar gak } \\
\text { murung begitu. Kamu di pondok terus } \\
\text { sih gak pernah metu-metu." } \\
\text { (MDM:23-2) }\end{array}$ \\
\hline 4 & $\begin{array}{l}\text { “Oke, kamu mau kita mampir ke rumah } \\
\text { Kang Dharma, Lin? } \\
\text { (MDM: 34-3) }\end{array}$ \\
\hline 5 & $\begin{array}{l}\text { "Rumahku dekat sini, Lin. Monggo } \\
\text { mampir. Atau kita makan dulu di Depot } \\
\text { Anugerah, di area parkiran?" } \\
\text { (MDM: 44-2) }\end{array}$ \\
\hline 6 & $\begin{array}{l}\text { "Ummik mau saya masakin apa? Monggo } \\
\text { kita makan bersama." } \\
\text { (MDM: 59-7) }\end{array}$ \\
\hline 7 & $\begin{array}{l}\text { "Mas mau saya buatkan sambel? Atau } \\
\text { nasi goring?" } \\
\text { (MDM: } 60-3 \text { ) }\end{array}$ \\
\hline 8 & $\begin{array}{l}\text { "Sempatkan dulu, Gus. Mumpung beliau } \\
\text { masih sehat. Kalau Njenengan tidak mau } \\
\text { saya ikut, ya, tidak apa apa. Saya bisa } \\
\text { pulang ke rumah ibu. Tapi Njenengan } \\
\text { antar abah dan ummik ziarah wali. Pasti } \\
\text { mereka berdua punya maksud ingin } \\
\text { mendoakan Njenengan." } \\
\text { (MDM: 99-4) }\end{array}$ \\
\hline 9 & $\begin{array}{l}\text { "Turuo kene sekali-sekali sama Birru, } \\
\text { Lin." } \\
\text { (MDM: 115-3) }\end{array}$ \\
\hline 10 & $\begin{array}{l}\text { "Suk, kowe dan Birru ta'ajak ya, Lin. } \\
\text { Abah iki pengen ngajak kamu sama } \\
\text { Birru sowan ke makam-makam }\end{array}$ \\
\hline
\end{tabular}

\begin{tabular}{|c|c|}
\hline & $\begin{array}{l}\text { waliyullah." } \\
\text { (MDM: 119-2) }\end{array}$ \\
\hline 11 & $\begin{array}{l}\text { "Zaki biar jemput anak buahmu. Kamu } \\
\text { aku yang njemput." } \\
\text { "Kalau gitu aku minta traktir es krim. Es } \\
\text { krim ketan hitam." } \\
\text { "Iya." } \\
\text { (MDM: 158-8) }\end{array}$ \\
\hline 12 & $\begin{array}{l}\text { "Nek Mas Arya ngantuk, ya, gantian aku } \\
\text { yang nyetir." } \\
\text { (MDM: 185-5) }\end{array}$ \\
\hline 13 & $\begin{array}{l}\text { "Hadiahnya? Seminggu lagi kuajak } \\
\text { nonton tari Retno Tinanding di } \\
\text { Surakarta. Pas banget itu sama yang } \\
\text { kamu tulis tadi soal Prajurit Estri." } \\
(\text { MDM: 208-1) }\end{array}$ \\
\hline 14 & $\begin{array}{l}\text { "Ini, Nduk, buat tambahan referensi. } \\
\text { Ta'tunggu tulisan selanjutnya." } \\
\text { (MDM: 211-7) }\end{array}$ \\
\hline 15 & $\begin{array}{l}\text { "Niatono ngabdi nang Yai Hannan. } \\
\text { Niatono ngaji neng Bu Nyai Hannan." } \\
\text { (MDM: 261-4) }\end{array}$ \\
\hline 16 & $\begin{array}{l}\text { "Konsentrasi membesarkan sekolah dan } \\
\text { pesantren mertuamu. Liyane dipikir } \\
\text { karo mlaku." } \\
\text { (MDM: 261-6) }\end{array}$ \\
\hline 17 & $\begin{array}{l}\text { "Sebentar, Lin. Ta'ambilkan oleh-oleh } \\
\text { buat Yai Jabbar." } \\
\text { (MDM: 283-5) }\end{array}$ \\
\hline 18 & $\begin{array}{l}\text { "Kalau kamu butuh bantuan, apa pun itu } \\
\text { hubungi aku, ya." } \\
\text { (MDM: 309-3) }\end{array}$ \\
\hline 19 & $\begin{array}{l}\text { "Besok nek pulang ta'gawani bibite ya, } \\
\text { tanduren, ojo lali diombe saben dino. } \\
\text { Ramuan ini sangat bermanfaat untuk } \\
\text { menyenangkan bojomu." } \\
\text { (MDM: } 317-5 \text { ) }\end{array}$ \\
\hline 20 & $\begin{array}{l}\text { "Metik suruh temu ros. Pitu ya. } \\
\text { Ta'buatkan jamu. Mumpung suamimu } \\
\text { rawuh." } \\
\text { (MDM: 344-6) }\end{array}$ \\
\hline 21 & $\begin{array}{l}\text { "Habis ini kita ke kota ya, Mas. Beli baju } \\
\text { buat Mas. Itu bajunya sudah kusut } \\
\text { begitu. Biar nanti kucuci." }\end{array}$ \\
\hline
\end{tabular}

Prinsip Maksim Kedermawanan...| 29 


\begin{tabular}{|l|l|}
\hline & (MDM: 363-2) \\
\hline 22 & $\begin{array}{l}\text { "Gak papa, Lin. Ummik sudah sehat kok. } \\
\text { Wes di situ sek ae, sekalian bulan madu." } \\
\text { (MDM: 369-1) }\end{array}$ \\
\hline 23 & $\begin{array}{l}\text { "Inggih. Besok Ummik mau dibawain } \\
\text { apa? Singkong? Pete? Pisang? Duren?" } \\
\text { (MDM:369-6) }\end{array}$ \\
\hline 24 & $\begin{array}{l}\text { "Mas Birru istirahat ya, pasti capek } \\
\text { semaleman nyetir. Aku buatkan wedang } \\
\text { jahe bentar." } \\
\text { (MDM: 376-4) }\end{array}$ \\
\hline
\end{tabular}

Berdasarkan hasil penelitian yang peneliti lakukan, terdapat 24 tuturan yang mengandung prinsip maksim kedermawanan sesuai dengan pendapat Leech (Solihin, 2019: 341) yang menjelaskan bahwa prinsip maksim kedermawanan adalah prinsip dimana penutur dapat bersikap murah hati dengan mengurangi keuntungan pada dirinya dalam berkomunikasi dan lebih melihat bagaimana cara agar lawan tuturnya bisa mendapatkan keuntungan dalam kegiatan berkomunikasi. Salah satu tuturan yang mengandung prinsip maksim kedermawanan dilakukan oleh Kang Dharma kepada lawan tuturnya. Dharma Wangsa yang biasa dipanggil dengan sebutan Kang Dharma adalah lurah di pondok tempat Alina menimba ilmu dulu. Kang Dharma adalah laki-laki yang tenang seperti Yudhistira, yang sabar berwatak samudera, yang mampu menguasai segala nafsu. Kang Dharma sering meminjamkan buku kepada Alina karena ia tahu hidup Alina begitu membosankan. Ia memberi banyak pengetahuan di tengah kesibukan yang Alina jalani. Ia selalu menjaga jarak dengan Alina karena ia menghormati Alina, calon menantu Kiai Hannan, sahabat kiai mereka. Kang Dharma adalah orang yang dermawan. Kedermawanan Kang Dharma dapat dilihat pada tuturan berikut.

\section{Kang Darma : “Ini nomorku, hubungi aku kalau ada apa-apa dengan anak- anak. Kamu juga boleh bercerita kapan saja kamu mau." (Anis, 2019: 20)}

Tuturan tersebut terjadi ketika Kang Dharma berada di rumah Kiai Hannan, mertua Alina. Kang Dharma datang mengantarkan beberapa anak yatim yang akan disekolahkan di tempat Kiai Hannan. Tuturan tersebut mengandung prinsip maksim kedermawanan, Kang Dharma memberikan nomor telepon kepada Alina karena ia melihat kesedihan begitu nyata di wajah Alina, matanya merah, kelopaknya basah, dan bulu-bulu matanya berair. Ia bersedia mendengarkan cerita Alina dan berharap agar beban yang ditanggung Alina dapat berkurang. Kemudian kedermawanan Kang Dharma juga terdapat pada tuturan berikut.

Kang Darma : "Rumahku dekat sini, Lin. Monggo mampir. Atau kita makan dulu di Depot Anugerah, di area parkiran?" (Anis, 2019:44)

Percakapan tersebut terjadi antara Kang Dharma dan Alina pada suatu sore, saat Alina dan Aruna berziarah di makam Ki Ageng Hasan Besari. Tuturan Kang Dharma memenuhi prinsip maksim kedermawanan, ia menawarkan Alina untuk mampir ke rumahnya atau makan di sebuah depot yang terletak di area parkiran. Saat itu Kang Dharma tahu keadaan Alina yang tidak sedang baikbaik saja, Kang Dharma menyaksikan 
Alina terisak di depan pusara sambil merapal doa, seorang diri, tanpa suaminya. Sikap kedermawanan kang Dharma kembali terlihat pada percakapan berikut.

\begin{tabular}{ll} 
Kang Darma & $:$ "Lin?" \\
Alina & $:$ "Eh, nggih." \\
Kang Darma & $:$ "Nomormu \\
& masih yang \\
& \multicolumn{2}{l}{ lama 'kan?" } \\
Alina & $:$ "Inggih." \\
Kang Darma & $:$ "Kalau kamu \\
& butuh bantuan, \\
& apa pun itu \\
& hubungi aku, \\
& ya." (Anis, \\
& 2019: 309).
\end{tabular}

Percakapan tersebut terjadi antara Kang Dharma dan Alina di rumah Mbah Kung. Tuturan Kang Dharma mengandung prinsip maksim kedermawanan, ia menawarkan bantuan kepada Alina. Ia tahu Alina menyembunyikan beban di hatinya, tapi ia sangat menghormati Alina, ia tidak bertanya apapun, dan siap membantu jika Alina membutuhkan.

Prinsip maksim kedermawanan juga terdapat pada tuturan yang dilakukan oleh Aruna. Sebagai seorang sahabat, Aruna mengenal Alina dengan begitu dekat dan dapat merasakan beban yang sedang ditanggung oleh Alina. Aruna lah yang sering menghibur Alina di tengah tuntutan ketat untuk hapalan. Aruna cantik dan lincah seperti Banowati dalam pewayangan. Alina mengenal Aruna sebagai seorang sahabat yang sangat loyal dan baik. Prinsip maksim kedermawanan dalam tuturan Aruna dapat dilihat pada data berikut.

Aruna : "Wajahmu lho, Lin, kucel gini. Piye to, kamu ini?

Mestinya habis

nikah lak ayumu

makin

mencorong? Lha,

ini kok redup?"

Aku memeluknya erat sambil mengoloknya sok tahu. Aruna selalu peka (Alina).

Aruna : “Ta'pamitke Bu Nyai, ya? ta'ajak ke salon kamu." Saat aku belum sempat mengangguk, dia sudah ngeloyor mencari ummik dan beliau memperbolehkan.

Begitulah Aruna, si ceria, dan sangat pandai membawa diri. (Anis, 2019: 22)

\section{Aruna : "Makanya kamu kuajak ke salon, biar gak murung begitu. Kamu di pondok terus sih gak pernah metu-metu."}

(Anis, 2019: 23)

Kedua percakapan tersebut terlihat jelas mengandung prinsip maksim kedermawanan, Aruna sebagai sahabat Alina yang menyadari wajah Alina semakin redup, pucat, dan tidak bergairah segera mengajaknya pergi ke salon untuk perawatan kecantikan, ia meminta izin langsung ke mertua Alina meskipun Alina belum memberi jawaban ataupun anggukan. Ia tahu Alina sangat sibuk dengan urusan pondok pesantren milik mertuanya itu. Ia mengajak Alina ke salon agar Alina 
dapat sedikit melupakan beban yang ada dipikiran.

Prinsip maksim kedermawanan kembali ditunjukkan oleh Aruna pada tuturan yang ia lakukan dengan Alina. Hal tersebut dapat dilihat pada data berikut.

Alina

: "Run, bawa aku ke makam Mbah Kiai Ageng Hasan Besari."

Dia terhenyak. Menyalakan mesin mobilnya.

Aruna : "Tegalsari jetis, Ponorogo?"

Aku mengangguk (Alina).

Aruna : “Oke, kamu mau kita mampir ke rumah Kang Dharma, Lin?" (Anis, 2019:34).

Percakapan tersebut terjadi antara Aruna dengan Alina pada saat perjalanan menuju makam Mbah Kiai Ageng Hasan Besari di Tegalsari jetis, Ponorogo. Saat itu Aruna tahu ada luka di hati Alina. Ia menawari Alina untuk mampir ke rumah Kang Dharma karena rumah Kang Dharma tidak jauh dari makam Mbah Kiai Ageng Hasan Besari. Aruna tahu Kang Dharma adalah lakilaki yang diam-diam dirindukan oleh Alina.

Kemudian prinsip maksim kedermawanan juga ditunjukkan pada tuturan yang dilakukan Alina. Alina, tokoh utama dalam novel ini memiliki sikap santun, tangguh, bijak, dan juga dermawan. Hal tersebut dapat dilihat pada data berikut.

$\begin{array}{ll}\text { Alina } & \text { : “Ummik mau saya } \\ & \text { masakin apa? } \\ & \text { Monggo kita makan } \\ & \text { bersama." }\end{array}$

Ummik

: "Ummik mau sambel tempe kemangi. Mbak-mbak tadi bikin, Lin. Tapi gak podo karo bikinanmu." Aku tersenyum.

Memasang sandal ke kedua kaki ummik. Beliau tidak tahan dingin. Aku melipat mukenanya. Lalu menuntunnya ke ruang tengah. Aku di sisi kanan. Mas Birru di sisi kiri (Anis, 2019: 59-60).

Tuturan Alina kepada mertuanya yang biasa ia panggil dengan sebutan ummik memuat prinsip maksim kedermawanan. Alina menawarkan diri untuk membuatkan masakan ummiknya dan mengajak makan bersama. Bagi Alina ummik adalah anugerah terbesar dalam hidupnya. Ummik mencintai Alina sedalam ibu kandungnya sendiri. Ummik adalah satu-satunya alasan Alina bertahan di rumah tersebut. Kemudian kedermawanan Alina kepada Ummik kembali ditunjukkan pada percakapan berikut.

$\begin{array}{ll}\text { Alina } & \text { : “Ummik, } \\ & \text { sebenarnya kami } \\ & \text { mau pulang siang } \\ & \text { ini. Tapi Mas } \\ & \text { Birru ngajak } \\ & \text { nginep. Ummik } \\ & \text { gak papa, ta?" } \\ \text { Ummik } \quad \text { : } & \text { Gak papa, Lin. } \\ & \text { Ummik sudah } \\ & \text { sehat kok. Wes } \\ & \text { disitu sek ae, } \\ & \text { sekalian bulan } \\ & \text { madu." Ummik }\end{array}$

Prinsip Maksim Kedermawanan...| 32 
terus tersenyum

(Anis, 2019: 368).

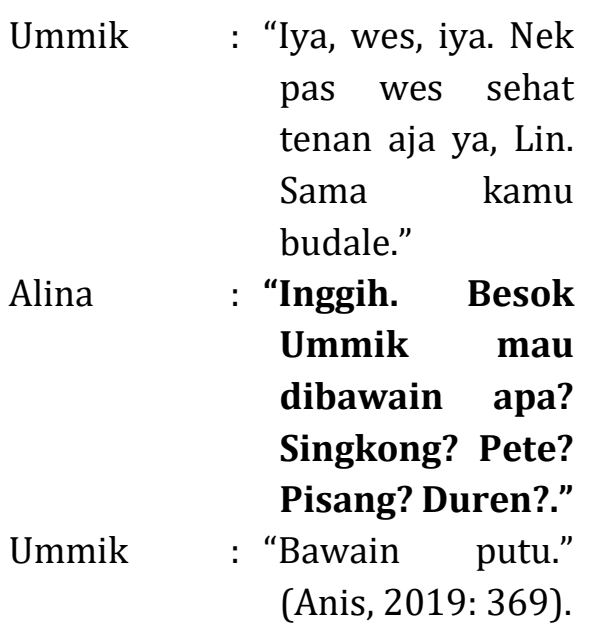

Percakapan antara Alina dan Ummik tersebut terjadi lewat telepon. Saat itu Alina dan Birru sedang berada di rumah Mbah Kung, mereka video call Ummik untuk meminta izin menginap. Pada percakapan pertama tuturan Ummik memuat prinsip maksim kedermawanan, ketika Alina meminta izin untuk menginap di rumah Mbah Kung dengan senang hati Ummik memberi izin, bahkan Ummik memberi kesempatan pada Alina dan Birru untuk bulan madu di sana. Kemudian pada percakapan kedua, prinsip maksim kedermawanan ditunjukkan melalui tuturan Alina. Ketika Ummik sudah memberikan mereka izin untuk menginap Alina menawari Ummik dengan berbagai makanan yang ada di tempat Mbah Kung.

Alina Suhita, yang terluka di kerajaannya sendiri dan mampu memendamnya dalam-dalam, namun terlihat tegar dan tetap bersikap santun. Alina sangat menghormati suaminya. Setiap hari ia menyiapkan segala kebutuhan suaminya, meskipun tidak ada kehangatan yang ia terima. Ia akan menaklukkan Gus Birru dengan kelembutan kasih sayangnya.

$\begin{array}{ccc}\text { Alina : "Mas mau saya } \\ \text { buatkan } \\ \text { sambel? Atau } \\ \text { nasi goreng?" } \\ \text { Gus Birru : "Enggak. Gak } \\ \\ & \text { usah," sahutnya } \\ & \text { (Anis, 2019: 60) }\end{array}$

Pada percakapan tersebut prinsip maksim kedermawanan ditunjukkan oleh Alina, meskipun Gus Birru menolak niat baiknya. Alina tidak tahu mengapa ia begitu mencintai Gus Birru meskipun Gus Birru masih melanggengkan sikap dinginnya. Sikap acuh yang ditunjukkan Gus Birru dan kasih sayang Ummik yang tumpah ruah membuat Alina yakin bahwa kendaraan menuju kebahagiaan adalah pengorbanan. Prinsip maksim kedermawanan kembali ditunjukkan Alina pada percakapan berikut.

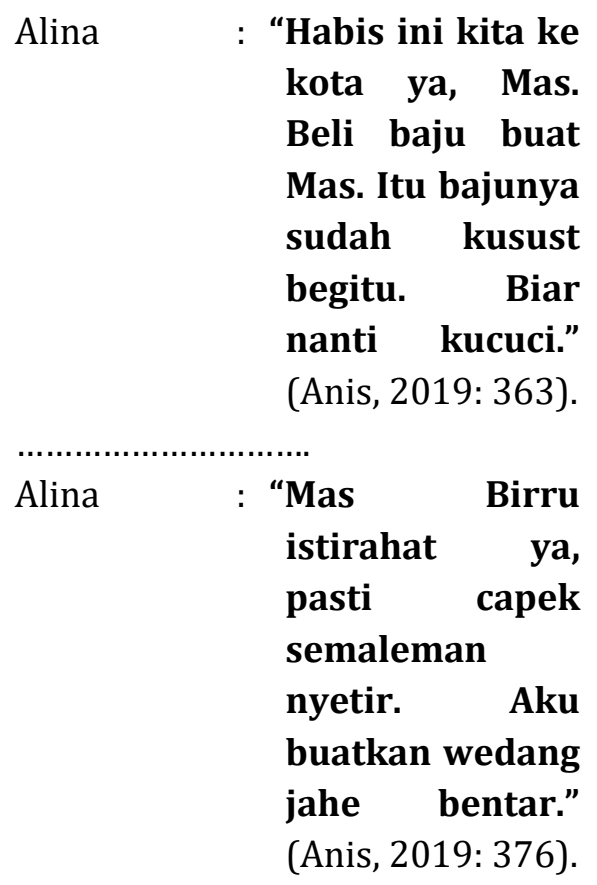

Kedua data di atas merupakan tuturan Alina yang ditujukan kapada Gus Birru. Tuturan tersebut terjadi ketika Gus Birru menyusul Alina ke Prinsip Maksim Kedermawanan...| 33 
rumah Mbah Kung, ketika Gus Birru sudah mulai melunak, Gus Birru yang beku sudah mencair, Gus Birru yang angkuh sudah berangsur hangat. Gus Birru yang angkuh telah takluk dengan pesona feminim perempuan Jawa yang sudah melekat dalam jiwa dan raga Alina, dan Gus Birru yang ternyata merindukan suara mengaji Alina. Sinar matanya memancarkan kerinduan pada Alina.

Kedua tuturan Alina tersebut memenuhi prinsip maksim kedermawanan. Pada tuturan pertama Alina mengajak Gus Birru pergi ke kota untuk membelikan Gus Birru baju karena Gus Birru memakai kemeja putih berlengan pendek yang sudah kusut dan lusuh dan Gus Birru tidak membawa baju ganti. Kemudian pada tuturan kedua Alina mempersilahkan Gus Birru untuk beristirahat dan akan membuatkannya wedang jahe karena Alina tahu Gus Birru pasti lelah nyetir semalaman, ia menembus malam sampai subuh sendirian, ia hanya mengenakan celana jins dan kemeja putih berlengan pendek, tidak membawa jaket, padahal daerah rumah Mbah Kung sangat dingin.

Prinsip maksim kedermawanan juga ditunjukkan oleh kedua orang tua Alina, seperti pada data berikut.

\begin{tabular}{|c|c|}
\hline Abah & $\begin{array}{l}\text { :Kowe ki rabi, } \\
\text { Nduk, tapi } \\
\text { niatono mondok } \\
\text { lagi." Ini nasihat } \\
\text { abahku di awal } \\
\text { pernikahan kami. }\end{array}$ \\
\hline Abah & $\begin{array}{lr}\text { : } & \text { Niatono } \\
\text { nangabdi } \\
\text { Hannan. Niatono }\end{array}$ \\
\hline & $\begin{array}{l}\text { ngaji neng Bu } \\
\text { Nyai Hannan." }\end{array}$ \\
\hline Alina & : "Inggih, Bah.” \\
\hline
\end{tabular}

Abah : "Ilmune Kiai
Hannan dan Bu
Nyai iki uakeh.
Kudu iso nitis
neng awakmu.
Kowe saiki wes
puterane."
Aku mengangguk sambil menahan
haru (Alina).
Ibu
:
monsentrasi
membesarkan
sekolah dan
pesantren
mertuamu.

Liyane dipikir karo mlaku." Ini nasihat ibuku (Anis, 2019: 261)

Pada percakapan tersebut dapat dilihat bahwa tuturan kedua orang tua Alina mengandung prinsip maksim kedermawanan. Mereka mengikhlaskan Alina untuk tinggal bersama mertuanya. Mereka menyerahkan Alina untuk membantu mertuanya membesarkan pondok pesantren Al-Anwar. Sejak kecil, kedua orang tua Alina sudah mendoktrinnya bahwa segala cita-cita dan tujuan hidupnya dipersembahkan untuk Pesantren Al-Anwar, pesantren mertuanya. Maka, Alina harus berusaha keras agar layak menjadi pemimpin di sana. Sejak kecil Alina dipondokkan di pesantren tahfidz. Kiai dan Bu Nyai Hannan mengusulkan agar Alina kuliah di jurusan Tafsir Hadis meskipun ia sangat ingin kuliah di jurusan sastra, kemudian saat Alina masih semester tujuh Kiai Hannan memintanya untuk pindah pesantren dan meninggalkan kuliah agar ia bisa lebih lanyah hapalan di pesantren barunya. Kedua orang tua Alina setuju saja asal itu keinginan Kiai 
dan $\mathrm{Bu}$ Nyai Hannan. Alina juga menurutinya.

Alina sangat menjiwai perannya di pesantren tersebut dengan baik, ia menghabiskan waktu untuk melayani kedua mertuanya yang biasa ia panggil dengan sebutan Abah dan Ummik. Segala sesuatunya ia nikmati selayaknya orang mondok. Penuh tirakat. Penuh perjuangan. Ia menjalani semua dengan tanpa beban. Lahir batin sudah ia persembahkan untuk Al-Anwar.

Prinsip maksim kedermawanan juga ditujukkan dalam tuturan Abu Raihan Albirruni, yang biasa dipanggil dengan sebutan Birru, Gus Birru, atau Mas Birru.

\begin{tabular}{|c|c|}
\hline Rengganis & $\begin{array}{l}\text { : “Hadiahnya } \\
\text { dong?” }\end{array}$ \\
\hline \multirow[t]{5}{*}{ Gus Birru } & $\begin{array}{l}\text { : "Hadiahnya? } \\
\text { Seminggu lagi }\end{array}$ \\
\hline & $\begin{array}{lr}\text { kuajak } & \text { nonton } \\
\text { tari } & \text { Retno }\end{array}$ \\
\hline & $\begin{array}{l}\text { Tinanding di } \\
\text { Surakarta. Pas } \\
\text { banget itu sama } \\
\text { yang kamu tulis }\end{array}$ \\
\hline & tadi soal \\
\hline & Prajurit Estri." \\
\hline \multirow[t]{4}{*}{ Rengganis } & $\begin{array}{l}\text { : Mauuu." Aku } \\
\text { terbelalak }\end{array}$ \\
\hline & $\begin{array}{l}\text { gembira. Melihat } \\
\text { pertunjukan }\end{array}$ \\
\hline & $\begin{array}{l}\text { budaya, apalagi } \\
\text { tari, adalah hal } \\
\text { yang membuatku }\end{array}$ \\
\hline & $\begin{array}{l}\text { antusias. Apalagi } \\
\text { berkaitan dengan } \\
\text { yang tadi kutulis. }\end{array}$ \\
\hline \multirow[t]{2}{*}{ Gus Birru } & $\begin{array}{l}\text { :Oke, kurang } \\
\text { ndak }\end{array}$ \\
\hline & hadiahnya?" \\
\hline Rengganis & $\begin{array}{l}\text { : "Ndak, } \\
\text { cukup." }\end{array}$ \\
\hline
\end{tabular}

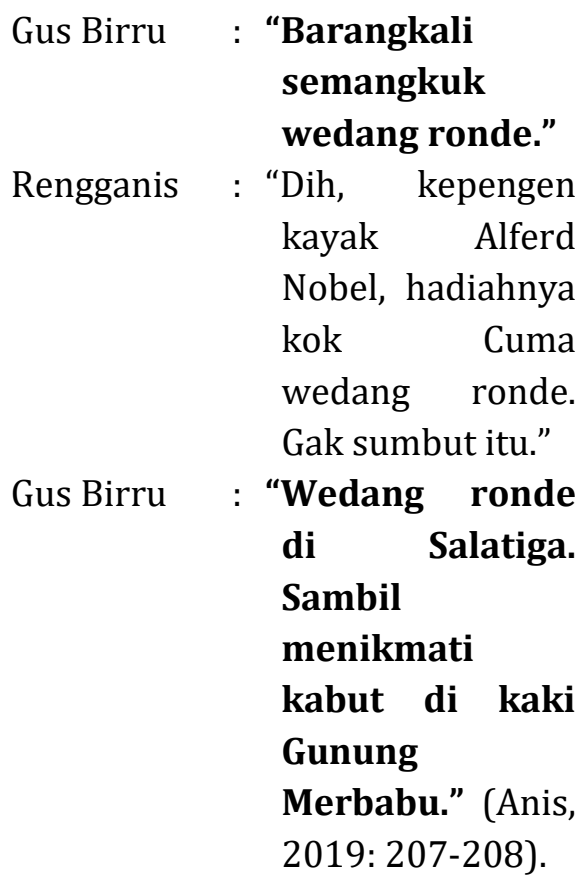

Tuturan Birru pada percakapan tersebut mengandung prinsip maksim kedermawanan. Percakapan tersebut terjadi pada siang hari disebuah warung penyet bernama Warung Maharani. Percakapan tersebut terjadi pada pertemuan pertama antara Gus Birru dan Rengganis. Gus Birru yang biasa Rengganis panggil dengan sebutan Mas Birru menawarkan berbagai hadiah kepada Rengganis, ia mengajak Rengganis menonton pertunjukan tari, kemudian ia kembali menawari semangkuk wedang ronde di Salatiga. Jogja-Salatiga bukan jarak yang dekat. Semangkuk wedang ronde di sanatentu jadi hadiah yang spesial. Pada pertemuan tersebut Mas Birru kembali menujukkan kedermawanannya, seperti pada data berikut.

Gus Birru : “Ini, Nduk, buat tambahan referensi. Ta'tunggu tulisan selanjutnya." 


$$
\begin{aligned}
\text { Rengganis : } & \text { Makasih, Mas.” } \\
& \text { (Anis, 2019: 211- } \\
& \text { 212). }
\end{aligned}
$$

Percakapan tersebut terjadi di parkiran sebelum mereka berpisah, pergi dari warung Maharani. Mas Birru memberi buku yang masih bersegel dengan judul Queen, Empress, Concubine, tentang perempuan-perempuan penguasa sejak zaman kuno sampai modern. Ia memberikan buku tersebut agar dijadikan sebagai bahan tambahan referensi bagi tulisan-tulisan Rengganis. Tuturan Birru pada percakapan di bawah ini juga menunjukkan prinsip maksim kedermawanan.

$\begin{array}{ll}\text { Gus Birru } & : \quad \text { "Zaki biar njemput } \\ & \text { anak buahmu. Kamu } \\ & \text { akau yang njemput." } \\ \text { Rengganis } & : \text { "Kalau gitu aku } \\ & \text { minta traktir es krim. Es } \\ & \text { krim ketan hitam." }\end{array}$

Gus Birru : “Iya," senyumku makinmengembang.

Rengganis selalu punya cara menghapus kemarahanku.

Rengganis : "Trus anter aku makan steak. Mas pasti sudah siapkan rentetan kalimat amarah. Jadi aku harus siap amunisi biar gak lemah letih lesu kalau Mas marah. Biar string aku."

Aku tergelak (Gus Birru). (Anis, 2019: 158-159).

$\begin{array}{ll}\text { Gus Birru } & \text { "Mau apa lagi, } \\ & \text { hmm?" Aku bertanya } \\ & \text { gemas. }\end{array}$

Rengganis : "Enggak wes, gak ada. Mau minta anter ke Sembilan pesantren itu kok kaya gak sopan dan aleman. Minta sangu aja yang banyak, boleh ya, Pak Bos?"

Gus Birru

“Oke, Nduk. Kabari

kalau lusa berangkat. Kami semua nunggu. 0jo PHP, lho." (Anis, 2019:159).

Percakapan tersebut terjadi lewat telepon antara Gus Birrru dengan Rengganis. Pada percakapan tersebut terlihat tuturan Gus Birru memenuhi prinsip maksim kedermawanan, ia yang bersedia menjemput Rengganis dan bersedia menuruti kemauan Rengganis untuk dibelikan es krim ketan hitam dan steak. Kemudian Gus Birru kembali bertanya apa lagi yang diinginkan oleh Rengganis. Rengganis menjawab dengan bercanda, ia meminta sangu yang banyak. Gus Birru kembali menyanggupi permintaan Rengganis.

\section{SIMPULAN}

Berdasarkan hasil penelitian dan pembahasan, dapat disimpulkan bahwa dalam novel Hati Suhita Karya Khilma Anis terdapat maksim kedermawanan. Maksim kedermawanan dapat diketahui melalui dialog antartokoh yang ditampilkan oleh penulis. Jumlah maksim kedermawanan dalam novel ini sebanyak 24 tuturan.

\section{DAFTAR PUSTAKA}

Anis, Khilma. 2019. Hati Suhita. Yogyakarta: Telaga Aksara.

Chaer, Abdul. 2010. Kesantunan Berbahasa. Jakarta: Rineka Cipta.

Silmi, Nadhira Izzatur. 2015. "Fenomena Teori Kesantunan Bahasa Grice Pada Media Cetak Jawa Pos Sportaiment". http://s3.amazonaws.com/academia.edu. documents/36178868/.Diunduh pada 20 November 2019.

Prinsip Maksim Kedermawanan...| 36 
Solihin, Asep. dkk. 2019 "Analisis Kesantunan Berbahasa Pada Novel Me And My Heart Karya Eva Riyanti Lubis". Dalam PAROLE Uurnal Pendidikan Bahasa dan Sastra Indonesia). Nomor 3, volume 2. https://journal.ikipsiliwangi.ac.id/index. php/parole/article/view/2778.Diunduh pada 14 Oktober 2019.

Solihin, Asep. dkk. 2019. "Analisis Kesantunan Berbahasa pada Novel Me And My Heart Karya Eva Riyanti Lubis". Dalam Parole Jurnal Pendidikan Bahasa dan Sastra Indonesia. Nomor 3, Volume 2. https://journal.ikipsiliwangi.ac.id/index. php/parole/article/view/2778. Diunduh pada 14 Oktober 2019.

Sugiyono. 2016. Metode Penelitian Kuantitatif, Kualitatif, dan $R \& D$. Bandung: Alfabeta. 